\title{
Building Collections through Purchase Suggestions in Academic Libraries
}

Kathia Ibacache

https://doi-org.colorado.idm.oclc.org/10.1080/01462679.2019.1666332

\section{Abstract}

\begin{abstract}
This research studies the fields contained in "Suggest a Purchase" forms from 100 university libraries, focusing on the data they can provide to subject specialists to make decisions about collection development. The research will consider whether the content of "Suggest a Purchase" forms may be used to aid subject specialists and collection development librarians to make decisions concerning the purchasing of books and other materials. Statistical evidence gathered through the "Suggest a Purchase" forms is analyzed to justify the relevancy of specific fields. The research examines whether patron-initiated purchases may offer data concerning collection gaps and trends in users' needs. The paper concludes with recommendations for best practices in the design and content of patron suggestion forms.
\end{abstract}

Keywords: Academic libraries, collection development, patron initiated purchases, suggest a purchase program, user driven acquisition

\section{INTRODUCTION}

Patron-driven acquisition (PDA) models have flourished over the past two decades in university libraries allowing users access to print and electronic materials of choice. One of these PDA models is the Suggest a Purchase program, which uses an online form that patrons submit on the library's webpage to request a book or other item for purchase. This Suggest a Purchase form varies according to the university library; some forms include few basic fields and other forms 
provide relevant fields, transforming this form into a tool that could gather information for collection development and drive meaningful user-experience.

This paper presents the results of a survey examining Suggest a Purchase forms from 100 university libraries in the United States. The author theorizes that certain fields contained in this form may render more benefits than just the acquisition of books requested by patrons. For instance, these fields may aid subject specialists and collection development librarians in answering questions relevant to the collection. In addition, the author hypothesizes that through the Suggests a Purchase program, university libraries may broaden their approach to userexperience by fostering a relationship with university patrons at large.

Interest in the Suggest a Purchase program grew after the author received useful information about the Spanish collection from students who submitted the Suggest a Purchase online form to request books at University of Colorado Boulder. This interaction triggered the following research question addressed in this study: Do the fields of the Suggest a Purchase form provide subject specialists meaningful data for making informed collection development decisions? This study also includes a recommendation for best practices when designing the Suggest a Purchase form.

\section{LITERATURE REVIEW}

\section{From Low Circulation to Patron-Initiative Purchase Models}

Numerous articles have been written about PDA programs, but few have focused on the Suggest a Purchase program. For this study, the author reviewed scholarship that was relevant to both patron-initiated purchase requests and user-experience published between 2010 and 2019. The idea of patrons suggesting a title for purchase is not new. In fact, other patron-driven acquisition models have gained relevancy to address poor circulation in academic libraries (Nixon, Freeman, 
and Ward 2010, 119-120) and compressed budgets and issues with publishing (England and Anderson 2019, 1), respectively.

Studies have shown that the bulk of librarian-selected items in collections in academic libraries rarely circulate (Nixon, Freeman, and Ward 2010; Levine-Clark 2010; Hodges, Preston, and Hamilton 2010; Tyler et al. 2010; Reynolds et al. 2010; Cramer 2013; Schroeder 2012). For instance, Nixon, Freeman, and Ward described the differences between the traditional just-incase model, where librarians selected books for purchase, and the just-in-time model where patrons' needs were the driving force for acquisitions, indicating that librarian-selected books have experienced low circulation rates since the late 1970's (119-120).

Scholarship has shown that patron-initiated purchase models have improved circulation. Comer Lorenzen, Fenner (2005) indicated that Indiana State University's adoption of a PDA model prompted the circulation of at least $80 \%$ of patron-requested titles (as cited in Herrera and Greenwood, 2011, 11). Similarly, Reynolds et al. (2010, 244), referring to Texas A\&M University Libraries (TAMU)'s user-driven acquisitions, reported a link between their Suggest a Purchase program and an increase in circulation numbers and library use (247). Comparably, Schroeder (2012) stated that the "Suggest-a-book" program at Brigham Young University produced more circulation than traditional acquisition during an evaluation of PDA programs (12). Therefore, PDA models such as the Suggest a Purchase program have opened one path for books to circulate and serve the particular needs of patrons.

\section{Concerns about Patron-Initiated Purchasing}

Patron-initiated purchasing models have raised some concerns among librarians who believe that while these models satisfy patrons' immediate needs, they may upset the balance of healthy collections (Hodges, Preston, and Hamilton, 2010, 219). Moreover, some authors state that 
subject specialists feel uncomfortable relinquishing too much collection decision-making power to constituents, fearing that their requests might be unsuitable for a university collection and might trigger large budgetary spending (Reynolds et al., 2010, p. 249).

Regardless, a study by Tyler et al. on the University of Nebraska-Lincoln Libraries added that patron-initiative monograph purchases were "topically suitable" and circulated considerably (175). Likewise, Shen et al. (2011) compared electronic book titles selected by patrons and librarians from the same PDA program list. The study suggested that patron and librarian book selections were more similar in content than expected, but that patrons tended to select titles that were more popular, supplementary, and specialized than librarians did (212-213).

Sens and Fonseca (2013) considered PDA as a business model favoring publishers and creating a personal library based on the Amazon giant book-purchasing model that invalidated librarian mediation. England and Anderson (2019) also inquired to what extent academic libraries could focus on individual requests covering patrons' "here and now" needs in relation to the mission of these libraries as repositories of human knowledge (9).

\section{User-Experience}

Sidorko and Woo (2008) reported on initiatives to foster a "service culture" within a university library staff, admitting the complexity of this task, which required time commitment and motivation (643). Ibacache (2019) suggests that fostering a relationship with patrons enhances the liaison work of subject specialists. Martin (2010) explored service to faculty as the need for subject librarians to get to know all their constituents. Mossop (2016) addressed two main notions, one assessing customer service as an organizational ethos and another considering students as customers, who expect not only quality education but also quality service (4-6). Reynolds et al. (2010) adds to the concept of improving user-experience with their Suggest a 
Purchase program at TAMU, through a survey that included 14 "satisfaction-driven questions." The respondents stated that they would like to be informed if a request had been approved and be notified when an approved title is available for check out (247-248).

This review has examined some of the literature connected with patron-initiated purchase requests models since 2010 and reported how this scholarship supported or dismissed the concept of user-driven acquisitions. It is clear from the different studies that patron-driven acquisition has had a positive impact on circulation. However, the literature also shows concern over the diminishing role of librarians as selectors and the value of university library's collections that are built based on patrons' needs. Finally, although much research has been published on certain PDA programs, this paper will focus on one area of the Suggest a Purchase program that has yet to be assessed. 


\section{METHODOLOGY}

This author examined quantitative data obtained from Suggest a Purchase online forms from 100 university libraries in the United States. The university libraries were identified from a list of academic libraries on the Association of Research Libraries (ARL) website. Similarly, the forms studied were accessible on the respective university libraries 'website. Although the forms varied in the number and the type of fields presented, this study focused on fields that were most relevant for collection development. The data was organized in Excel and statistical graphs were used to calculate the level of prevalence of each one of the fields covered in this study.

\section{RESULTS}

\section{The Fields}

Table 1 shows forty distinct fields found in the 100 forms studied. These fields may be divided in three categories: First, there are fields that identify the requester. These include name, e-mail, affiliation, department, phone, ID number, address, your campus, and your college. Second, there are fields that identify the requester's needs such as notification, needed by, hold item, and confirmation of submission. Third, there are fields that have the potential to guide collection development decision making. These fields include title, author, date of publication, comments, format, edition, source, reason, place of publication, series, material type, requested for course, editor, publisher, subject area, and cited in. 


\begin{tabular}{|c|c|c|c|}
\hline \multicolumn{4}{|c|}{ Fields and Percentage of Appearance } \\
\hline Field & $\%$ & Field & $\%$ \\
\hline Title & 100 & Requested for course & 17 \\
\hline E-mail & 99 & Material type & 17 \\
\hline Name & 98 & Editor & 16 \\
\hline Author & 94 & Publisher & 15 \\
\hline Date of publication & 82 & Subject area & 15 \\
\hline Status & 70 & Needed by & 14 \\
\hline ISBN & 70 & Address & 10 \\
\hline Comments & 70 & Reviewed or cited in & 7 \\
\hline Format & 54 & Your campus & 6 \\
\hline Department & 50 & Your college & 4 \\
\hline Edition & 42 & Other editions ok? & 1 \\
\hline Phone & 39 & OCLC number & 1 \\
\hline Source/URL & 36 & Library of Congress number & 1 \\
\hline Price & 34 & Where did you find title? & 1 \\
\hline Reason & 28 & Performance right needed & 1 \\
\hline Place of publication & 28 & Music publisher number & 1 \\
\hline Notification & 26 & Is book required for a course? & 1 \\
\hline Series & 21 & Video publisher number & 1 \\
\hline Hold Item & 20 & Confirmation of submission & 1 \\
\hline ID number & 17 & Location if oversees & 1 \\
\hline
\end{tabular}

Table 1. Fields found in 100 suggest a purchase forms.

\section{The Fields Explained}

Status: This field refers to the status of the requester, e.g. faculty, graduate student, undergraduate student, staff, alumni, community member, and other. The forms vary in how this field is labeled; whether referred to as affiliation, status, classification, or tell us about yourself, this field is found in $70 \%$ of the forms and is mandatory in $45 \%$ of them.

Format: The fields format and material type are used interchangeably to designate the type of material requested: book (print), eBook, $\mathrm{CD}$, thesis, patent, proceeding, journal, database, dataset, DVD, maps, score, subscription, streaming media, software, and subscription. Nonetheless, a few forms use the term format to specify between print and electronic (eBook) 
only. Format is found in $52 \%$ of the forms and is mandatory in $22 \%$ of these forms. $19 \%$ of the forms ask for material type, of which $8 \%$ make it a requirement.

Source: This field asks the requester to provide the URL from where the requester gathered title information.

Reason: Usually in the form of a text box, this field inquires as to why a title is needed, and thus provides additional information that could aid in the purchase decision. It answers the question: why should the library purchase this title? This field occurs in $28 \%$ of the forms and is mandatory in $7 \%$.

Hold Item: This field asks requesters if they would like a hold placed to ensure that they be the first to checkout the item.

Publisher: This field allows the requester to specify if they are interested in a specific publisher. Date Needed By: This field provides information as to the urgency of the request suggesting the library's ability to expedite requests if necessary. It answers the question: is this a rush request? A few university libraries offer a different form for urgent requests.

Notification: This field asks requesters whether they would like to be notified when the library receives the item and is ready for checkout, not whether the request is approved.

Figure 1 is a sample Suggest a Purchase form. The forms evaluated in this study contained some of the fields shown in figure 1 and a variety of other fields. Some forms were more comprehensive and included as many as seventeen fields. Other forms were more concise in design and contained as few as three fields. In terms of fields that are required, usually shown with an asterisk, there appears to be no consensus. Some forms specified only two required fields, while others required many more. 
Figure 1. Suggest a purchase form used at University of Colorado Boulder.

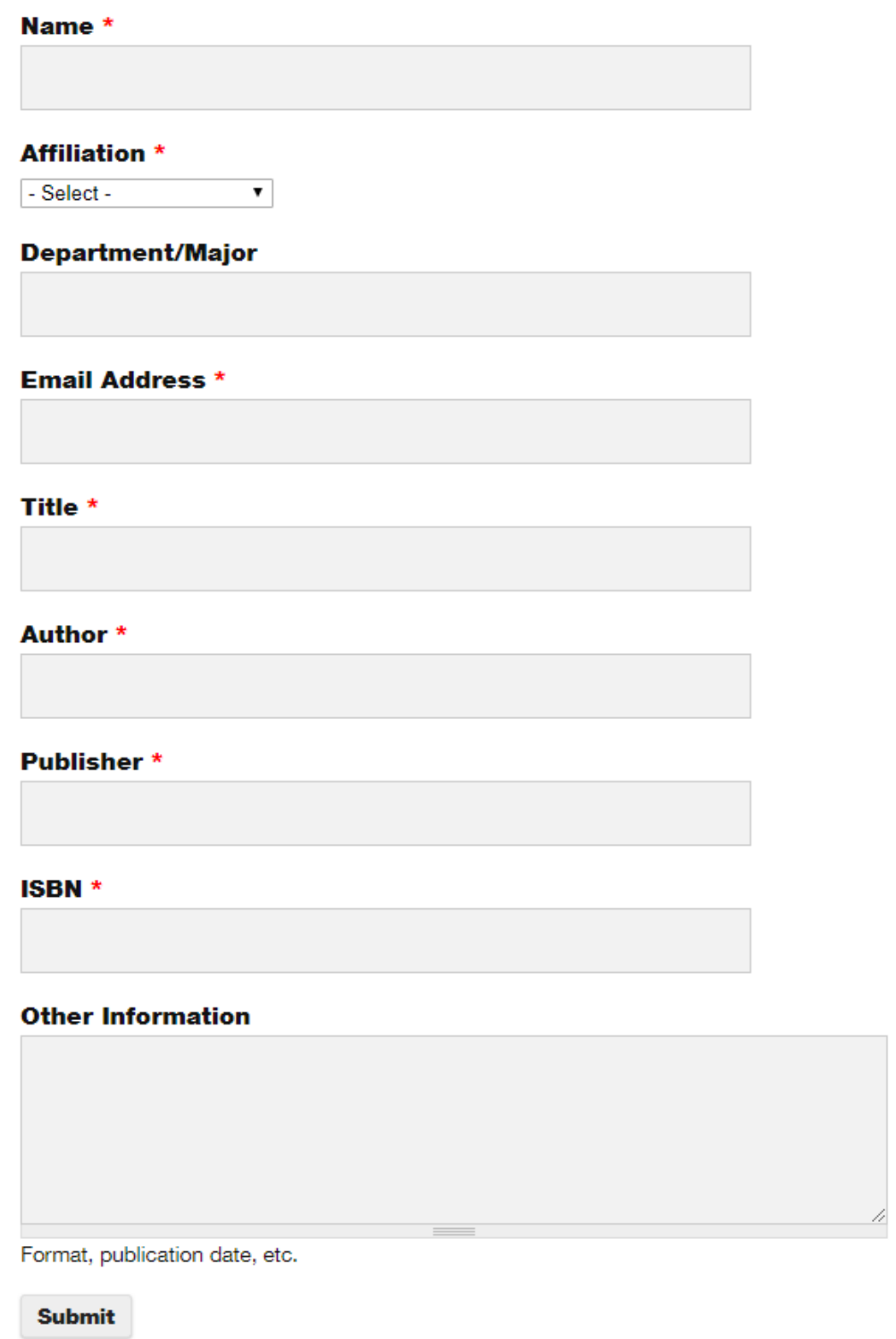

Figure 2 displays the frequency of appearance of item related fields. This shows that a majority of these university libraries include the fields: title, author, publisher, and date of publication. Approximately four out of ten forms include the edition field. In contrast, $72 \%$ of the forms that were studied do not contain the place of publication field and approximately less than one quarter of the forms include the series field. Figure 2 also illustrates low frequency of the editor and subject fields. 
Figure 2. Item related fields.

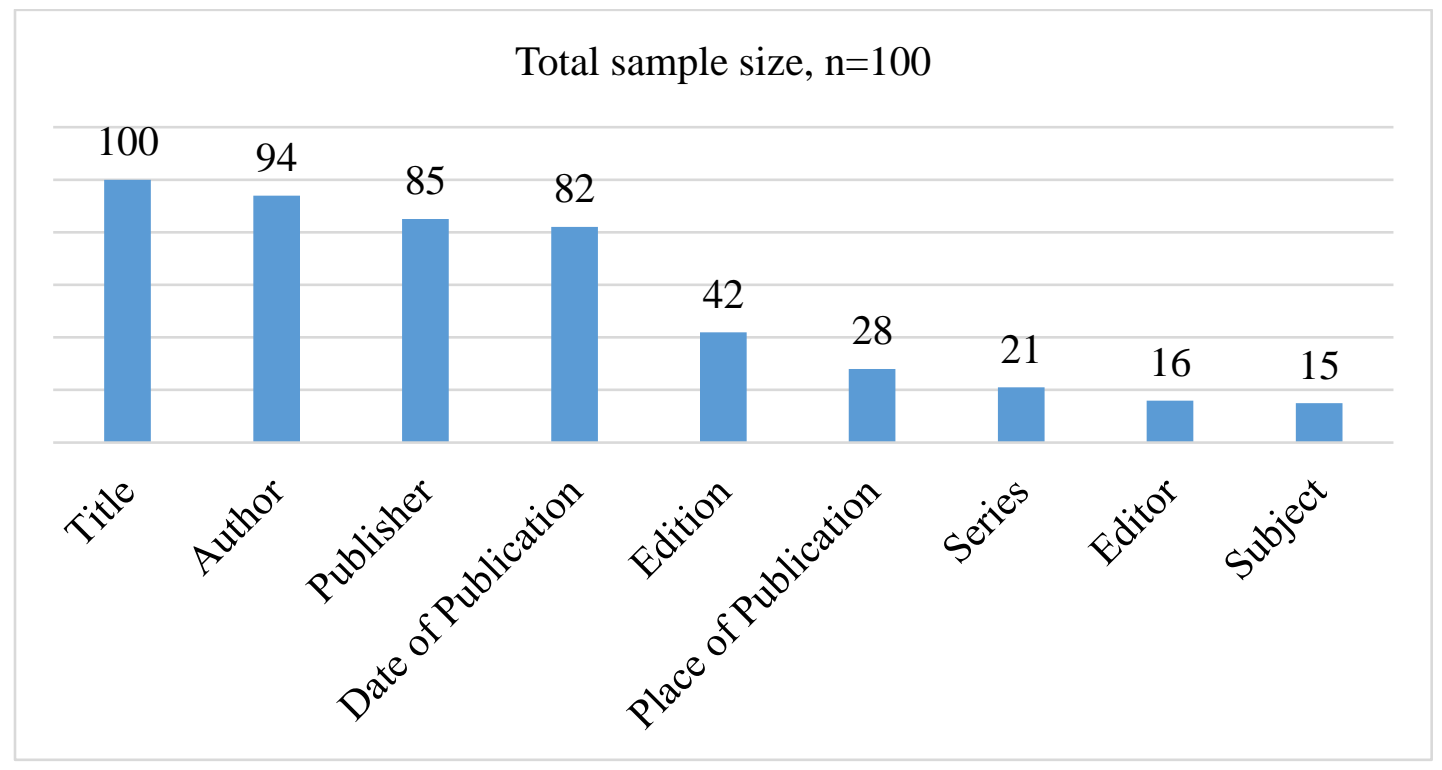

Figure 3 shows fields that have the potential to collect information that may be used for collection development decision making. The majority of fields allow for some sort of user input in regards to preferred format or material type and a place for comments. A minority of fields seek the reason for the request.

Figure 3. Fields with a potential to influence collection development.

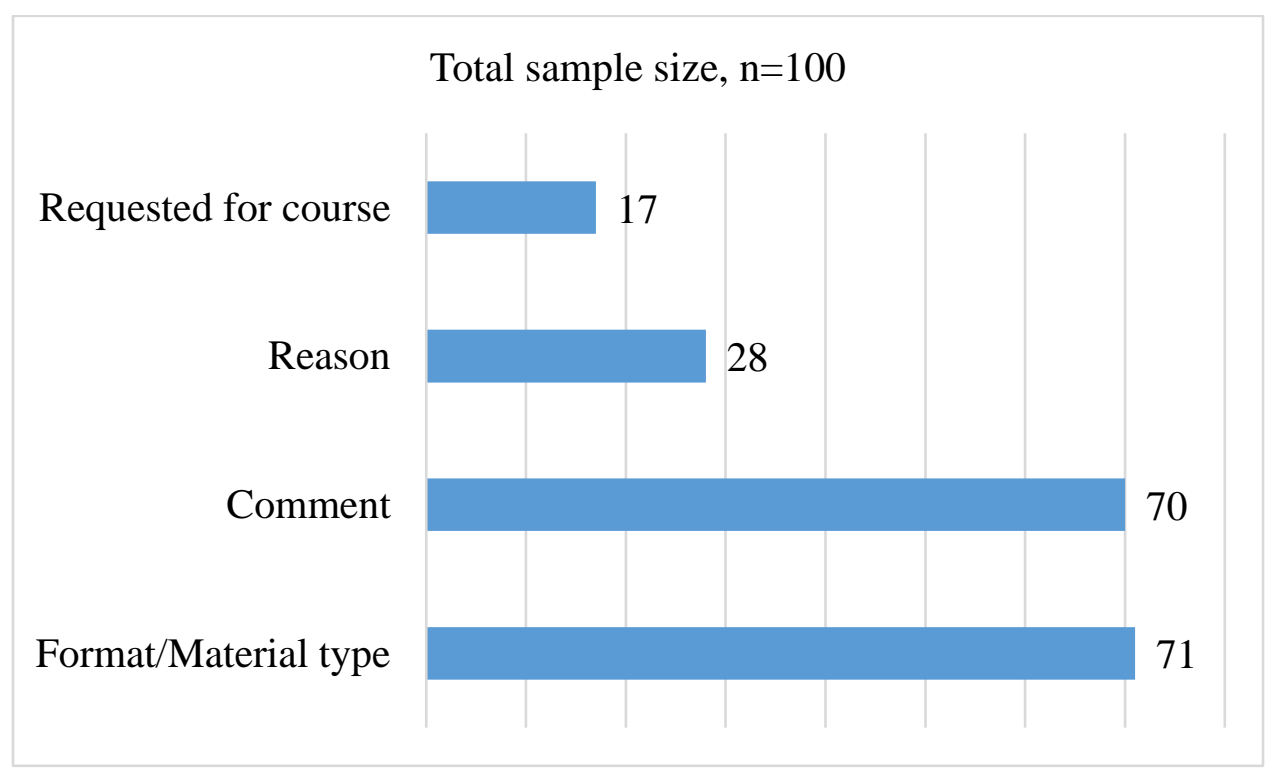


Figure 4 shows that only half of the forms surveyed inquire as to the department of requesters. In contrast, $70 \%$ of forms ask for their status. The fields of notification and date needed by have much lower frequencies of appearance.

Figure 4. Fields that identify the requester and their needs.

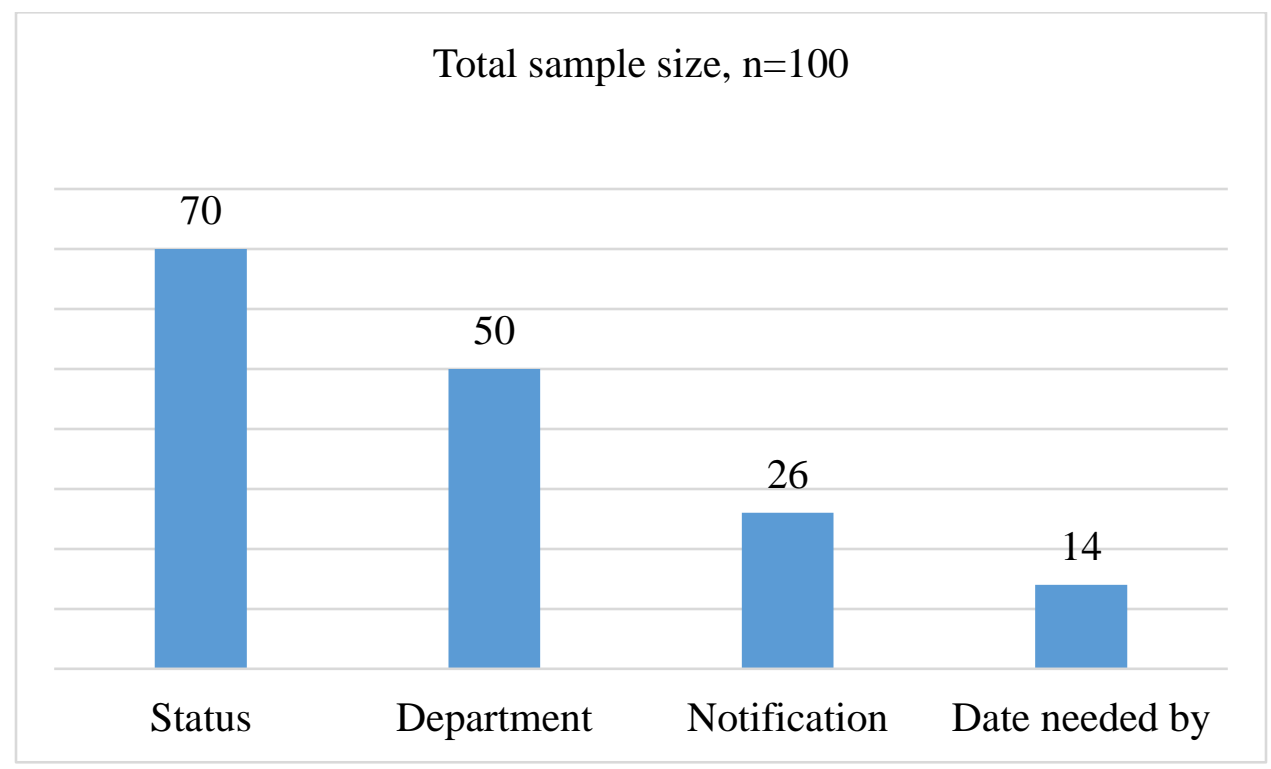

\section{DISCUSSION}

Do the fields of the Suggest a Purchase form provide subject specialists meaningful data for making informed collection development decisions?

An examination of the fields contained in 100 forms shows that the forms have the potential to collect data may be helpful to subject specialists and collection development librarians and may assist them in making informed decisions when purchasing a title. The relevance a university library gives to the Suggest a Purchase program will depend upon their collection development practices and policies. Nonetheless, this study hypothesizes that the connection this program offers with the real collection needs of university patrons, validates using this program methodically as a collection development tool. 
For instance, the field author -which appears in all forms - helps collection development librarians familiarize themselves with writers that are prominent and are part of the canon that students and faculty are favoring. Similarly, date of publication ( $82 \%$ of forms) and edition (only 42\%) are also important fields for faculty and students who are researching a given topic, especially when different publishers have published a title multiple times. While date of publication is well represented in the forms, edition appears underutilized. To illustrate, various editions of the same title may include different forewords or epilogues. From the point of view of the researcher, these distinctions may matter or reflect on the authoritativeness of a title. From the point of view of the librarian, these fields may help connect the decision making process to user needs, and minimize the risk of purchasing an incorrect or undesired version of the item.

The fields publisher (85\% of forms) and place of publication (only 28\%) also have unequal representation. The latter field offers a concealed merit that may not be evident to subject specialists and collection development librarians - namely, it provides useful information regarding the publishing house of a book, especially if the publisher is an international vendor. Anecdotally, a revealing conversation with a doctoral student brought attention to the fact that the acquisition of a book published by a large foreign publishing house, rather than an edition published in the country of origin of the author, may result in the loss of important elements that were present in the original version of the book. For example, a foreign publishing house may change the cover of a book to appeal to a specific foreign market, disassociating the publication from the original vision of the book in question. The fields publisher and place of publication have the potential to provide information that may be of consequence for researchers and thus important for librarians to consider when determining where to source foreign materials in general. 
The field reason appears underutilized (only $28 \%$ ), but like comments (70\%), this field may offer helpful information to subject specialists. The purposes underlying a request may vary from a collection gap, to a damaged item on the shelf, missing pages, or a small representation on a given subject. These open-ended fields allow opportunity to gather input on issues observed by professors and students, which may go unnoticed by librarians. For example, students looking for Spanish poetry might notice that certain poetry books on the shelf are in poor shape and thus may be ready for deselection or replacement. Alternatively, other patrons might notice that there are too few items on French dramaturgy. This information is crucial for subject librarians, as it helps them to identify issues within their collections that need attention. One explanation for the low representation of the field reason might be to avoid privacy intrusion. Some patrons may not want to be linked to a request that may be potentially embarrassing. The solution is to make reason a non-mandatory field. On balance, the benefit of information to be obtained from reason should outweigh privacy concerns and justify its inclusion.

The field format (54\% of forms) helps distinguish between a preference for an electronic or print source. Approximately half of the forms inquire regarding format, which shows that this field is not yet universally considered important. An interesting but underutilized field is subject area $(15 \%)$. This field often presents with a drop down menu that allows the requester to select the subject and subject specialist, presumably to whom the request will be forwarded. From the library's perspectives, this facilitates directing the requests to the right subject specialists. Another field with low representation, requested for course (17\%) may have value in helping subject specialists become acquainted with the curricular needs of a specific course.

Fields that are relevant to gathering demographics of the requesters, such as status $(70 \%)$ and department (50\%) are not universally utilized. These fields may provide a valuable insight. 
For example, subject specialists may notice that while a large percentage of graduate students are submitting requests, undergraduate students are barely doing so. Such information may prompt subject specialists to develop an action plan to publicize this program among these targeted groups. By informing patrons of the Suggest a Purchase program, subject specialists may foster communication as well as empower them to request titles that are meaningful to their collection needs.

Similarly, subject specialists may use the data from the field department to connect with departments that are not utilizing the Suggest a Purchase program. Having this field on the form assists subject specialists in examining possible reasons why some departments are proactive in submitting suggestions for purchase and why others are not. Can it be that a discipline has many gaps in its collection that need to be addressed? Or perhaps a department is accustomed to suggesting titles to complement its specific needs? Subject specialists may use data from this field for outreach purposes or to gather general information on a department's specific needs.

Last, the fields Date Needed By (14\%) and Notification (26\%) also appear undervalued. These fields play a significant role in managing the expectations of requesters and enhancing communication. Could the university library purchase, process, and have the item ready for checkout in a time that meets the needs of the patron? University libraries that include the field date needed by imply the capability to submit rush purchase orders and expedite requests. If this field is missing from the forms, however, university libraries are at risk of not meeting the expectations of requesters.

\section{RECOMMENDATION}

The Suggest a Purchase program is a tool that allows a user-centered approach to building collections. Depending on the design and fields incorporated into the forms, the Suggest a 
Purchase forms may collect relevant information that can guide librarians that make collection development decisions. Specific fields may also be used to promote communication and manage expectations of requesters. Based on the forms studied, the following practices are recommended.

Nearly all forms surveyed contain author, title, and date of publication fields. However, the representation of other fields that could collect useful information for collection development is uneven. Fields such as publisher, place of publication, and edition may also provide relevant information and should accompany the author and title fields. The use of these five fields together, may complete the data needed not only to purchase the correct item for the requester, but also to help librarians gather a fuller vision of the item needed in relationship with other items that may be related in subject matter or scope.

Forms should also include open-ended fields such as comments or reason, which invite the requester to share information and insight that goes beyond the mere identification of the material requested. The presence of these open-ended fields help librarians understand the request in context of the collection. These fields also could help draw attention to collections gaps, subject trends, damaged items, course collection needs, and other areas of concern for librarians that may otherwise go unnoticed. There appears to be no downside from gathering as much information as possible from requesters, especially input that could be shared among subject specialists and collection development librarians for the benefit of understanding collection needs.

However, the inclusion of fields in the Suggest a Purchase form is more complex than expected. When evaluating fields, it is recommended to consider the individual character of the university library and the university it serves. In the case of Georgetown University, whose form 
is the only one of the 100 forms that includes the field location oversees; this field makes sense for them. This university has a study center in Fiesole, Italy and a Center for Eastern Mediterranean Studies in Turkey. Similarly, Bates College is the only one who includes the field music publisher number in its form. In a conversation with a collection development librarian at Bates College, she stated that this field had been used to identify scores and to secure that the library was purchasing the exact item requested. However, this field is usually left unanswered. Patrons prefer providing a direct link to the version needed.

It is also recommended that forms be assessed and updated regularly to be effective and meaningful in terms of the data they provide. The forms covered in this paper are customized to accrue accurate data, nonetheless, not all the forms had the potential to do this. Some forms were minimal in the amount and type of fields; one form included three fields only: name, email, and title/collection recommendation, while other forms were more complicated to navigate; these forms were built with multiple pages. For example, one form consisted of a five-stage multi-page process. This setting may discourage requesters, who do not have the time to submit a request that takes long to complete.

Since university libraries usually have control over the type and number of fields, it is recommended that these forms include critical fields such publisher, place of publication, and subject area, all of which had under 30\% of representation. To illustrate, the clearest form, even though it has fourteen fields, is from the Claremont Colleges. The fields are distributed in one single page and include: name, email, select your college, tell us about yourself, your department/major, title, author, publisher, publication year, edition, ISBN, preferred format, needed by, additional notes/comments. 
To conclude, a step that may be helpful is to dispose of fields that are deem unnecessary. Unnecessary fields could be detected after consideration of data. If a field does not offer relevant data, collection development librarians may improve the form by incorporating only the fields that reveal data that could be useful for collection development and enhance communication with patrons. After all, the inclusion of too many fields may render unfriendly and, most importantly, may jeopardize the dual nature of these forms: as a service for requesters to communicate a collection need and as a tool for librarians to gather data that could aid collection development decisions.

\section{CONCLUSION}

This study seeks to heightens awareness of the usefulness of data contained in Suggest a Purchase submissions to make collection development decisions. To this end, the Suggest a Purchase form may be considered as one analytical tool to collect and evaluate information in the aggregate, guiding collection purchase decision-making. By trusting that patrons' requests are expressions of their genuine needs, the Suggest a Purchase program offers an opportunity for subject specialists and collection development librarians to build collections that are relevant to the specific needs of their constituents, improving collections and enhancing user-experience.

This model serves to cement a path of communication with patrons and to support their intellectual, curricular, and research needs. The evaluation of Suggest a Purchase forms from 100 university libraries indicate that there is no consensus regarding the amount and type of fields used in the form. Some universities omit critical fields that Could help collection development decision making and improve acquisition practices. Finally, having a thoughtfully designed form would furnish data that could be utilized in a continuous, methodical, and consistent manner by subject specialists and collection development librarians. More 
specifically, this data could assist in examining title suggestion trends, subject trends, areas of research, curricula collection needs, departments using this program, and the reasons why titles are been suggested.

\section{REFERENCES}

Association of Research Libraries. "Membership: List of ARL Members.” Accessed April 5, 2019. https://www.arl.org/membership/list-of-arl-members.

Comer, Alberta, Elizabeth A. Lorenzen, and Audrey Fenner (2005). "Biz of Acq - Is Purchaseon-Demand a Worthy Model? Do Patrons Really Know What They Want? Against de Grains 17 (1): 77. doi: 10.7771/2380-176X.4771.

Cramer, Carol Joyce. 2013. “All About Demand-Driven Acquisition.” The Serials Librarian 65 (1): 87-97. doi: 10.1080/0361526X.2013.800631.

England, Mark M., and Rick Anderson. 2019. "Demand-Driven Acquisition of Print Books: Applying $21^{\text {st }}$-Century Procurement Strategies to a $5^{\text {th }}$-Century Format." Collection Management 44 (2-4): 1-10. doi: 10.1080/01462679.2018.1564715.

Herrera, Gail, and Judy Greenwood. 2011. "Patron-Initiated Purchasing: Evaluating Criteria and Workflows.” Journal of Interlibrary Loan, Document Delivery and Electronic Reserve 21 (1-2): 9-24. doi: 10.1080/1072303X.2011.544602.

Hodges, Dracine, Cyndi Preston, and Marsha J. Hamilton. 2010. "Patron-Initiated Collection Development: Progress of a Paradigm Shift.” Collection Management 35 (3-4): 208-221. doi: 10.1080/01462679.2010.486968.

Ibacache, Kathia. 2019. "The Suggest a Library Purchase Program at the University of Colorado Boulder." Collection Management 45 (1):1-9. doi: 10.1080/01462679.2019.1650153.

Levine-clark, Michael. 2010. "Developing a Multiformat Demand-Driven Acquisition Model.” 
Collection Management 35 (3-4): 201-207. doi: 10.1080./01462679.2010.486965.

Martin, Julia A. 2010. "Understanding Faculty Needs: A Case Study at the University of Toledo." Journal of Library and Information Science, 36 (1): 16-35.

Mossop, Stephen. 2016. “Customer Service: What's the Big Deal?" In Customer Service in Academic Libraries: Tales from the Front Lines, edited by Stephen Mossop, 1-16. Waltham: Chandos Publishing.

Nixon, Judith M., Robert S. Freeman, and Suzanne M. Ward. 2010. "Patron-Driven Acquisitions: An Introduction and Literature Review." Collection Management 35 (3-4): 119-124. doi: 10.1080/01462679.2010.486957.

Reynolds, Leslie J., Carmelita Pickett, Wyoma vanDuinkerken, Jane Smith, Jeanne Harrell, and Sandra Tucker. 2010. "User-Driven Acquisitions: Allowing Patron Requests to Drive Collection Development in an Academic Library." Collection Management, 35 (3/4), 244-254. doi: 10.1080/01462679.2010.486992.

Schroeder, Rebecca. 2012. "When Patrons Call the Shots: Patron-Driven Acquisition at Brigham Young University.” Collection Building 31(1):11-4. doi: 10.1108/01604951211199128. Sens, Jean-Mark, and Anthony J. Fonseca. 2013. “A Skeptic's View of Patron-Driven Acquisitions: Is it Time to Ask the Tough Questions?” Technical Services Quarterly 30 (4): 359-371. doi: 10.1080/07317131.2013.818499.

Shen, Lisa, Erin Dorris Cassidy, Eric Elmore, Glenda Griffin, Tyler Manolovitz, Michelle Martinez, and Linda M. Turney. 2011. "Head First into the Patron-Driven Acquisition Pool: A Comparison of Librarian Selections Versus Patron Purchases.” Journal of Electronic Resources Librarianship 23 (3): 203-218. doi:

10.1080/1941126X.2011.601224. 
Sidorko, Peter Edward, and Esther Woo. 2008. "Enhancing the User Experience: Promoting a Service Culture through Customized Staff Training." Library Management 29 (8/9): 641-56. doi: 10.1108/01435120810917279.

Tyler, David C., Yang Yu, Joyce C. Melvin, Marylou Epp, and Anita M. Kreps. 2010. “Just How Right are the Customers? An Analysis of the Relative Performance of Patron-Initiated Interlibrary Loan Monograph Purchases." Collection Management 35 (3/4): 162-179. doi: $10.1080 / 462679.2010 .487030$. 